\title{
Erratum to: A new active CACTA element and transposition activity in ecotype differentiation of Arabidopsis
}

\author{
Kyong-Cheul Park $\cdot$ Nam-Il Park $\cdot$ Sun-Il Lee $\cdot$ \\ Kwang-Soo Kim $\cdot$ Young-Suk Chang · \\ Nam-Soo Kim
}

Published online: 13 June 2014

(C) The Genetics Society of Korea and Springer-Science and Media 2014

\section{Erratum to: Genes Genom (2014) 36:229-238 \\ DOI 10.1007/s13258-013-0161-x}

The affiliation of the second author of this article was changed. Please find correct affiliation in this erratum.

The online version of the original article can be found under doi:10.1007/s13258-013-0161-x.

\section{K.-C. Park · N.-S. Kim}

Institute of Bioscience and Biotechnology, Kangwon National

University, Hyoja-dong 192-1, Chunchon 200-701, Korea

\section{N.-I. Park}

Department of Plant Science, College of Life Sciences,

Gangneung-Won-ju National University, 7 Jukheon-gil,

Gangneung-si 210-702, Korea

\section{S.-I. Lee · N.-S. Kim $(\bowtie)$}

Department of Molecular Bioscience, BK21 Training Team,

College of Biomedical Science, Kangwon National University,

Hyoja-dong 192-1, Chunchon 200-701, Korea

e-mail: kimnamsu@kangwon.ac.kr

K.-S. Kim · Y.-S. Chang

Bioenergy Crop Research Center, National Institute of Crop Science, Rural Development Administration, Muan 534-833,

Korea 